Original Research Paper

\title{
Research Ethics and Overseas Fieldwork: Are Ethics Committees Oblivious of Cultural Differences?
}

\author{
Jones Adu-Gyamfi \\ University of Bradford, School of Social and International Studies, Bradford, BD7 1DP, UK
}

Article history

Received: 16-09-2014

Revised: 29-09-2016

Accepted: 12-03-2018

Email: j.adu-gyamfi@bradford.ac.uk

\begin{abstract}
Research ethics committees have come under increasing criticisms either for been toothless or too fierce. This has mainly come about as a result of the gap in theoretical expectations of research ethics and the experienced realities during fieldwork. In particular, ethics committees incur the displeasure of international students who undertake studies in their own sociocultural contexts. This paper presents a personal account of my experience as an international student in obtaining ethical approval for my doctoral research from a UK university. In this study, I challenge the validity of strict adherence to Western ethical framework in conducting research in non-western societies. With the increasing presence of non-western students in western universities, the paper argues for more flexibility in the ethical approval process to accommodate cultural differences. This would help to avoid situations where international students tell ethics committees what the committee would like to hear but do what they want to do while on fieldwork in their home countries.
\end{abstract}

Keywords: Overseas Fieldwork, Ethical Guidelines, Ethics Committee, Cross-Cultural Research

\section{Introduction}

The study of a contemporary phenomenon in its real-life context obligates the researcher to follow ethical practices of the highest standard (Yin, 2009). These standards are embodied in research ethical guidelines and frameworks that are policed by Research Ethics Committees, whose primary role is to 'protect the dignity, rights, safety and well-being of all actual or potential research participants' (Fistein and Quilligan, 2012:224). In the UK most research councils and professional associations have research ethics guidelines and most certainly all UK universities have ethical guidelines and research ethics committees. It is argued that ethics committees exist 'as much to protect researchers and institutions where research is carried out as those who may be the subjects of research' (Morrow, 2013). Nonetheless, there has been a growing call for rethink of research ethics and ethical approval processes (Haggerty, 2004; Beaulieu and Estalella, 2012; Van Den Hoonaard, 2001; Schrag, 2011; Dingwall, 2008). The situation is however different in Ghana; research governance is not given prominent attention in the country. Research supervisors are trusted to spot ethical concerns and guide students in undertaking their studies. The notable research governance framework in Ghana is in the area of health research where six institutional review boards were set up in 2004 under the sponsorship of European and Developing countries Clinical Trials Partnership to regulate research on human subjects.

As an international student from Ghana, where research governance is much more fluid, obtaining ethical approval from a UK university with a bureaucratic ethics approval process was a challenge. The intention of this paper is to draw attention that the checklist approach to research ethics approval needs reconsideration. I argue that it is paternalistic for research ethics committee in one country to determine how research in another country should be conducted, especially when the committee has little knowledge of practices in the other country. As argued by Hammersley (2006) researchers require detailed knowledge of the contexts of their study in order to weigh key ethical issues. Ethics committee members 
often do not have such detailed contextual knowledge; therefore the imposition of a bureaucratic framework irrespective of context is unethical. In spite of the numerous literature that suggest a need to consider cultural differences in the research process (Hudson and Taylor-Henley, 2001; Sue and Sue, 1990), ethics review processes continue to depict Euro-American culture.

\section{Ethical Approval Process}

In the Euro-American culture ethical standards include signed written consent form, adherence to confidentiality and anonymity of research participants and official access from gate-keepers. In accordance with the research governance framework of my university I applied for ethical approval before commencing the fieldwork. The university's ethical approval process stipulated maximum of 7 weeks to obtain a decision, however it took more than 3 months for me to receive a decision. This was due to the committee's belief that my research did not meet the university's ethical guidelines. After 3 months I received ethical approval via chair's action. The next section presents how I proposed to conduct the research and the ethical issues encountered in the fieldwork. The table below depicts how I responded to some of the university's checklist for ethical approval:

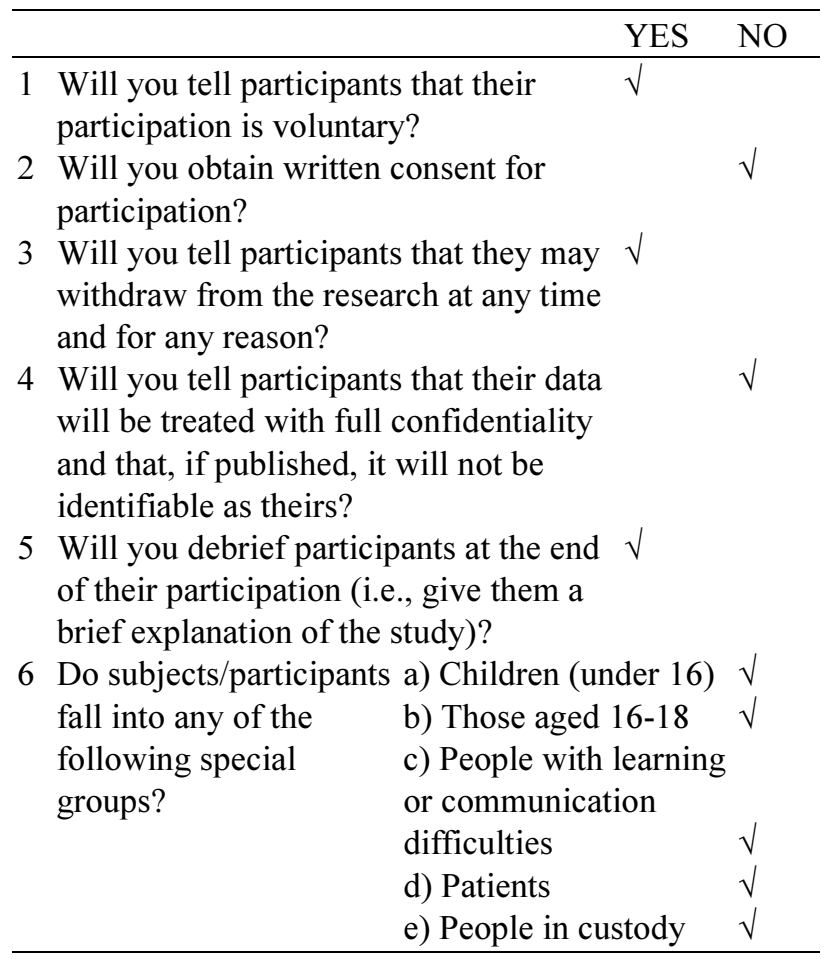

The committee members were primarily dissatisfied with the questions that I had answered as no.

\section{Access to Vulnerable Population}

Right at the beginning of the approval process it was discovered that a discrepancy existed between UK bureaucratic framework and practices in Ghana. The first major discrepancy was the ethics committee questioning whether I had obtained Criminal Records Bureau clearance as the research was with a vulnerable population. The university's ethical guidelines state that 'Criminal Records Bureau clearance should always be sought when conducting research with children under the age of 16' (emphasis mine). However, unlike the UK, Criminal Records Bureau clearance is not a requirement in Ghana to come into contact or work with 'vulnerable groups'. As it can be seen from the table, my research involved people classed as 'special group' hence the committee's insistence on obtaining a CRB clearance.

\section{Consent}

Another issue that the research ethics committee was dissatisfied with in my proposal was consent. The university's ethics guidelines required researchers to obtain written consent:

Researchers must obtain and record consent from participants...in writing...signed consent forms should be stored separately from the research data.

However, in my study I proposed to regard consent as an ongoing verbal process (Thomas and O'Kane, 1998) whereby participants could withdraw their participation without having to give reasons anytime they wished. In this way participants were not required to sign written consent form agreeing to participate in the research. Kellett (2005) argues that informed consent is not simply a question of informing participants about the research and asking them to sign a consent form. Similarly, Simons (2009) has noted that asking participants to sign a consent form is insufficient for good ethical practice and in some contexts inappropriate. Also, some researchers who had conducted studies in Ghana had concluded that it is inappropriate to ask participants to sign consent forms in Ghana (Twum-Danso, 2008; Boakye-Boaten, 2010).

The research ethics committee members were unhappy with my decision not to obtain signed written consent form. To satisfy the committee that I had indeed obtained consent, the committee wanted me to tape record the 'ongoing verbal consent'. I objected to that explaining that recording participants giving oral consent even before they had agreed to take part in the study was unethical and also it would be inappropriate and burdensome to seek consent off-tape and ask participant to repeat themselves giving consent just so it could be captured on tape. 


\section{Anonymity}

The third area of contention with my university's ethics committee was around the issue of confidentiality and anonymity. Confidentiality and anonymity obligate the researcher to ensure that no harm befalls any research participant and the university's ethical guidelines stated that 'participants must be assured that their anonymity will be respected at all times unless otherwise determined by law'. Therefore the committee was unhappy with my decision not to offer blanket anonymity. It is argued that respecting confidentiality and anonymity enables participants to freely share their experiences with the researcher (Cree et al., 2002) since the nature of interaction between researchers and participants in qualitative research invites disclosure of personal intimate information (Duncan et al., 2009).

The principle of anonymity has however been challenged. Simons (2009) has questioned the essence of anonymity arguing that denying identity is an ethical issue which according to him is as damaging as naming people in reports. This is supported by Silverman's (2006) argument that some people may actually want to be identified in research reports and feel let down if their identity is concealed. Also, according to Walford (2005) anonymity does not promote transparency in research. He argues that it is useful for research sites and participants to be known so that other researchers can verify the validity of accounts. In view of these assertions, I required participants who wanted to be identified in my study to sign a disclosure form in order to satisfy the ethics committee.

\section{Discussion}

The experience shared in this study hopefully highlights that ethics should not be treated as a onedimensional issue (Van Den Hoonaard, 2001). With the increasing admission of students from non-western countries to universities in western countries, there is the need for more flexibility in ethical guidelines to take account of cultural differences. These non-western students often undertake research in their homecountries, therefore as argued by Morrow (2013) although broad ethical guidelines are useful, there should be 'room for the personal ethical choices of the researcher'. Similarly, Measor and Sikes (1992) have argued that researchers personal context impacts on the research process and also highlight that failure to recognise the researcher's role in the research process has both methodological and ethical ramifications.

Committee members must accept that signed written consent is not always possible either due to some disability such as multiple scoliosis/Duchene muscular dystrophy or due to problems of illiteracy where a substantial proportion of citizens in some developing countries use thumb-print instead of signature. Ethics committees should accept the legitimacy oral consent; after all in face-to-face researches the researcher first speaks to the participant to elicit their participation before a written consent form is handed out if the participant agrees to participate.

Moreover, the requirement to have signed consent form is highly contested (Reinharz, 1993; Van Den Hoonaard, 2001). Reinharz (1993) has argued that it is problematic and coercive to require written consent from research participants. As also argued by Charbonneau (1984) an individual's informed consent as 'the cornerstone of all western ethical codes' is however difficult to apply in situations characterised by secrecy, especially in research on sensitive topics (Van Den Hoonaard, 2001). Research ethics committees should accept that anonymity and signed written consent need not 'always be a gold standard of proper research ethics' (Beaulieu and Estalella, 2012). Perhaps it may be useful for the committee to invite international students to discuss their proposal and answer questions directly to clarify areas that committee members have concerns. This will greatly reduce students' anxiety levels, time wasted and help demystify the ethical approval process. This will also avoid incidence of international students just telling ethics committees what the committee would like to hear but the students doing what they want to do in the field.

While research ethics committees are instituted for very good reasons I believe that subjecting all research proposals to mandatory ethical review is unnecessary and a waste of time. I share the views of Dyck and Allen (2013) that the responsibility for determining the ethics of non-medical research should be transferred to researchers and their supervisors. In this vein, ethics committees can enhance the capability of supervisors to guide students to conduct ethical research by offering more ethics in research training opportunities. Until such time that the regulation of social science research is discontinued (Schrag, 2011; Dingwall, 2008), there should be more flexibility in ethics guidelines and ethical approval process, especially in respect of research undertaken by nationals of non-western countries in their homecountries, for they know more about the practices in their home-countries.

\section{Conclusion}

Research ethics committees have endured a number of criticisms (Edwards et al., 2004; Dyck and Allen, 2013). There have equally been a number publications in defence of research ethics committees (Garrard and Dawson, 2005; Dunn, 2013). This 
requires research ethics committees to maintain delicate balance to satisfy both sides of the debate. As argued by Fistein and Quilligan (2012) research ethics committees must ensure that research participants are 'adequately protected from unjustified risk' while also avoiding overly paternalistic inferences. Ethics committee members should not be oblivious of cultural differences in the research environment.

\section{Acknowledgment}

I am grateful to the Department of Social Work, Royal Holloway, University of London for their seminar for postgraduate research students in June 2012. The article was first presented at that seminar.

\section{Funding Information}

The research on which this article is based received no external funding.

\section{Ethics}

The article is based on research that received ethical approval.

\section{References}

Beaulieu, A. and A. Estalella, 2012. Rethinking research ethics for mediated settings. Inform. Commun. Society, 15: 23-42. DOI: 10.1080/1369118X.2010.535838

Boakye-Boaten, A., 2010. Changes in the concept of childhood: Implications on children in Ghana. J. Int. Soc. Res., 3: 104-115.

Cree, V.E., H. Kay and K. Tisdall, 2002. Research with children: Sharing the dilemmas. Child Family Soc. Work, 7: 7-56.

DOI: $10.1046 / \mathrm{j} .1365-2206.2002 .00223 . \mathrm{x}$

Charbonneau, R., 1984. Ethics in human research. IDRC Rep., 13: 20-21

Dingwall, R., 2008. The ethical case against ethical regulation in humanities and social science research. J. Acad. Soc. Sci., 3: 1-12. DOI: $10.1080 / 17450140701749189$

Duncan, R.E., S.E. Drew, J. Hodgson and S.M. Sawyer, 2009. Is my mum going to hear this? Methodological and ethical challenges in qualitative health research with Young People. Soc. Sci. Med., 69: 1691-1699. DOI: 10.1016/j.socscimed.2009.09.001

Dunn, M., 2013. Getting the justification for research ethics review right. J. Med. Eth., 39: 527-528. DOI: 10.1136/medethics-2012-100943

Dyck, M. and G. Allen, 2013. Is mandatory research ethics reviewing ethical? J. Med. Eth., 39: 517-520. DOI: 10.1136/medethics-2011-100274
Edwards, S., S. Kirchin and R. Huxtable, 2004. Research ethics committees and paternalism. J. Med. Eth., 30: 88-91.

DOI: $10.1136 /$ jme.2002.000166

Fistein, E. and S. Quilligan, 2012. In the lion's den? Experiences of interaction with research ethics committees. J. Med. Eth., 38: 224-227.

DOI: $10.1136 /$ medethics-2011-100124

Garrard, E. and A. Dawson, 2005. What is the role of the research ethics committee? Paternalism, inducements and harm in research ethics. J. Med. Eth., 31: 419-423. DOI: 10.1136/jme.2004.010447

Haggerty, K.D., 2004. Ethics creep: Governing social science research in the name of ethics. Qualitative Sociol., 27: 391-414. DOI: 10.1023/B:QUAS.0000049239.15922.a3

Hammersley, M., 2006. Are ethics committees ethical? Qualitative Res., 2: 4-8. PMID: 10276083

Hudson, P. and S. Taylor-Henley, 2001. Beyond the rhetoric: Implementing a culturally appropriate research project in first nations communities. Am. Indian Culture Res. J., 25: 93-105.

Kellett, M., 2005. How to Develop Children as Researchers. 1st Edn., Paul Chapman Publishing, London, ISBN-10: 1412908299, pp: 184.

Measor L. and P. Sikes, 1992. Visiting Lives. In: Studying Teachers' Lives, Goodson, I.F. (Ed.), Routledge, London, pp: 209-233.

Morrow, V., 2013. The ethics of social research with children and young people-an overview.

Reinharz, S., 1993. On Becoming a Social Scientist. 4th Edn., Transaction, New Brunswick, N.J.

Schrag, Z.M., 2011. The case against ethics review in the social sciences. Res. Eth., 7: 120-131. DOI: $10.1177 / 174701611100700402$

Silverman, D., 2006. Interpreting Qualitative Data. 3rd Edn., Sage Publications, London, ISBN-10: 1446200205, pp: 448.

Simons, H., 2009. Case Study Research in Practice. 1st Edn., Sage Publications, Los Angeles, ISBN-10: 0761964231, pp: 200.

Sue, D.W. and Sue, D., 1990. Counselling the Culturally Different. 1st Edn., John Wiley and Sons, New York.

Thomas, N. and C. O'Kane, 1999. Experiences of decision-making in middle childhood: The example of children 'looked after' by local authorities. Childhood, 6: 369-387. DOI: $10.1177 / 0907568299006003005$

Twum-Danso, A., 2008. A cultural bridge, not an imposition: Legitimizing children's rights in the eyes of local communities. J. History Child. Youth, 1: 391-413. DOI: 10.1353/hcy.0.0023 
Van Den Hoonaard, W.C., 2001. Is research-ethics review a moral panic? Canad. Rev. Sociol., 38: 19-36. DOI: 10.1111/j.1755-618X.2001.tb00601.x

Walford, G., 2005. Research ethical guidelines and anonymity. Int. J. Res. Method Educ., 28: 83-93. DOI: $10.1080 / 01406720500036786$
Yin, R., 2009. Case Study Research: Design and Methods. 1st Edn., Sage Publications, London, ISBN-10: 1412960991, pp: 219. 